\title{
Reduced graphene oxide/polypyrrole/nitrate reductase deposited glassy carbon electrode (GCE/RGO/PPy/NR): biosensor for the detection of nitrate in wastewater
}

\author{
Mohammad Faisal Umar ${ }^{1}$. Abu Nasar ${ }^{1}$
}

Received: 27 July 2018 / Accepted: 17 October 2018 / Published online: 27 October 2018

(c) The Author(s) 2018

\begin{abstract}
In the present work, a novel biosensor (GCE/RGO/PPy/NR) based on the nanocomposite of reduced graphene oxide (RGO), polypyrrole (PPy) immobilized by nitrate reductase (NR) was developed on a glassy carbon electrode (GCE). The conductive nanocomposite (RGO/PPy) was synthesized by in situ oxidative polymerization of pyrrole in the presence of RGO in acidic medium. A facile and green path was employed to synthesize RGO from graphene oxide (GO). This was performed by a novel route using Abelmoschus esculentus vegetable extract as a stabilizing and reducing agent for GO. The composite of reduced graphene oxide and polypyrrole (RGO/PPy) was deposited onto GCE with subsequent deposition of NR enzyme on the GCE/ RGO/PPy to develop GCE/RGO/PPy/NR biosensor. The surface morphology and structural features of the composites were studied by Fourier transform infrared (FTIR) spectroscopy, scanning electron microscopy (SEM) and transmission electron microscopy (TEM). The electrochemical behavior and electrocatalytic activity of the biosensor were examined by cyclic voltammetry at different scan rates $\left(20-100 \mathrm{mV} \mathrm{s}^{-1}\right)$ in the synthetic nitrate solution. The developed bio-anode achieved a maximum current density of $4.24 \mathrm{~mA} \mathrm{~cm}^{-2}$ at a scan rate of $100 \mathrm{mV} \mathrm{s}^{-1}$ for $10 \mathrm{mM}$ sodium nitrate solution.
\end{abstract}

Keywords Biosensor $\cdot$ Nitrate detection $\cdot$ Glassy carbon electrode $\cdot$ Nitrate reductase $\cdot$ Cyclic voltammetry

\section{Introduction}

Nitrogen is one of the most essential nutrients for all living bodies. However, living organisms are unable to take nitrogen directly from the environment. To maintain the growth and metabolism of aquatic organisms, nitrogen usually in the form of nitrate is essential. However, if the concentration of nitrogen reaches beyond a safe limit, it may cause a serious impact on the environment. During recent years, social accomplishments have added to as much as $30 \%$ enhancement in nitrogen compounds in the atmosphere as compared to natural means of fixation (Ward et al. 2005). The common sources of nitrogen in the environment are fertilizers, animal manure, agricultural, domestic and industrial wastewater, inadequate dumping of industrial and municipal wastes,

Abu Nasar

abunasaramu@gmail.com

1 Department of Applied Chemistry, Faculty of Engineering and Technology, Aligarh Muslim University, Aligarh 202002, India atmospheric deposition, rock weathering, leakage in septic systems and point source discharges (Sohail and Adeloju 2016; Ebrahimi-Gatkash et al. 2017). Further, to accomplish the growing demand for agricultural food, there has been increasing use of pesticides and fertilizers throughout the world (Qamruzzaman and Nasar 2014a, b). Moreover, various other poisonous substances such as dyes, heavy metals, miscellaneous organic impurities are being introduced into the water bodies from different activities such as textile, tannery, coke industries and refineries (Shakoor and Nasar 2016, 2018; Azimi et al. 2017). Most of the contaminants contain nitrogen or associated with nitrogenous compounds and increase the nitrogen level of the water (Rezakazemi et al. 2018b). Human consumes nitrogen through drinking water, fruits and vegetables. The high level of nitrate in drinking water causes serious threat due to the conversion of nitrate to nitrite in the body which interferes with oxygen transport in the blood (Sharma and Bhattacharya 2017). It has been reported that the high consumption of nitrate in the human body may cause the formation of more toxic species such as nitrite, nitric oxide and $\mathrm{N}$-nitroso compounds and consequently impose serious health issue (Sohail and 
Adeloju 2016). These species are very dangerous and cause gastric cancer, blue baby syndrome (blood methemoglobinemia) and metabolic disorder to human and animals. These disorders are especially dangerous for infants due to their immature physical stature and the vulnerability of their neural development to impeded oxygen transport (Moorcroft et al. 2001). Hence, to limit the consumption of nitrate, the US Environmental Protection Agency (EPA) set the maximum contaminant level (MCL) of nitrate and nitrite in drinking water supplies at 10 and $1 \mathrm{ppm}$, respectively, (USEPA). The drinking water containing nitrate and nitrite more than the MCL consumed by infants below the age group 6 months poses serious illness with the symptoms that include shortness of breath and blue baby syndrome (US-EPA). Such infants may die if not treated properly.

Owing to the considerable environmental and dangerous effects of nitrate, its removal from the aquatic ecosystem is essential. However, the effective removal and control of any contaminant are based on accurate knowledge of its concentration. Thus, the detection and determination of nitrate concentration in different environmental matrices such as water and wastewater, soils sediments and plants are of primary importance. During past and recent years, a number of different methods such as spectrophotometry (Edwards et al. 2001; López Pasquali et al. 2007; Pasquali et al. 2010), gas chromatography coupled with mass spectrometry (Tsikas et al. 1997), ion chromatography coupled with electrospray ionization tandem mass spectrometry (Blount and ValentinBlasini 2006), disk electrode alert system (Soropogui et al. 2006), miniaturised photometry (Tu et al. 2010), surfaceenhanced Raman spectroscopy (Gajaraj et al. 2013), electrochemical (Beer and Sweerts 1989), membrane technology (Rezakazemi et al. 2017, 2018a), electrophoresis (Gao et al. 2004), hydrodynamic sequential injection (Somnam et al. 2008), fluorescence (Mohr et al. 1997; Huber et al. 2001), and microplate fluorimetry (Ciulu et al. 2018) have been used for the detection of nitrate in different types of samples. However, most of these techniques require expensive instrumentation, and in several circumstances, they are not suitable for instant field tests.

On the other hand, the biosensors have received considerable attention for the development of a simple portable tool having the capability for the detection of nitrate even present in a very low concentration. During recent years, there has been increasing attention in developing the biosensor with high sensitivity and fast response (Lu et al. 2008). Over the years, the development of different types of biosensors into convenient, portable, single use, disposable devices has made them a commercial achievement. The usage of such biosensors reduces the effect of cross-contamination, drift, surface fouling and carry-over (Wang et al. 2008). Determination of nitrate by employing the enzymatic biosensor has been broadly considered (Moorcroft 2001). In this context, the nitrate reductase (NR), a catalyst suitable for encouraging a reduction in the hazardous nitrate species, has been utilized as the bio-recognition component for the manufacturing of nitrate distinguishing biosensor (Barbier et al. 2004; Sohail et al. 2012; Sohail and Adeloju 2016). The electrochemical detection of nitrate using biological catalyst NR for the reduction of nitrate into nitrite is considered a more sophisticated approach (Kiang et al. 1978; Atmeh and Alcock-Earley 2011). This is because the NR effectively improves the electrode sensitivity and selectivity toward nitrate reduction (Cosnier et al. 2008). Another advantage of using NR that it can be easily extracted from the plant, animal and microorganism including fungal sources.

Further, during recent years there has been increasing interest to enhance stability, sensitivity and toughness of the biosensor to make it appropriate for the business use. Incorporation of metal nanoparticles (Sohail and Adeloju 2016), colloidal dirt (Barbier et al. 2004) and redox polymers is the state-of-the-art technology in the development of biosensors. Another idea that the vast majority of the earlier workmanship concentrates on is screen printing/thick film microfabrication innovation (Sohail and Adeloju 2009). Thick film methods are appropriate for large-scale manufacturing of the enzyme electrodes to be employed in the application of nitrate biosensors. In the present work, a novel biosensor (GCE/RGO/PPy/NR) based on the composite of reduced graphene oxide (RGO), polypyrrole (PPy) and NR was developed on a glassy carbon electrode (GCE). The efficacy of the biosensor has been demonstrated by using synthetically contaminated wastewater containing nitrate ion.

\section{Experimental}

\section{Chemical and reagents}

Graphite flakes obtained from Alfa Aesar and sulfuric acid, potassium permanganate, hydrochloric acid, sodium nitrate, pyrrole and hydrogen peroxide each obtained from Merck, India, were used in the present study. Nitrate reductase obtained from Aspergillus niger (Sigma-Aldrich) was used as received. The water used throughout the experiment was obtained by deionization followed by double distillation. The water used was purified by double distillation of deionized water. This doubly distilled deionized water (DDW) was used throughout the experiment.

\section{Preparation of graphene oxide (GO)}

Modified Hummer's method (Paulchamy et al. 2015; Alam et al. 2017) was employed for the preparation of graphene oxide from graphite. $0.5 \mathrm{~g}$ graphite was taken and mixed with sodium nitrate in a round-bottom flask. The blend of 
the graphite and sodium nitrate was added into concentrated sulfuric acid followed by stirring for $30 \mathrm{~min}$. The reaction mixture was kept in an ice water bath, and then potassium permanganate was added to it under stirring. After that, the mixture was kept at $35^{\circ} \mathrm{C}$ for $2 \mathrm{~h}$. Afterward, $25 \mathrm{~mL}$ of distilled water was poured into the flask leading to the appearance of the brownish solution. After $15 \mathrm{~min}, 10 \mathrm{~mL}$ of $30 \%$ hydrogen peroxide and $100 \mathrm{~mL}$ of warm DDW were added which turned the color of the solution from brownish to yellowish brown color. Finally, the resultant filtered mass was washed with hydrochloric acid and DDW. The GO, so obtained, was dried in an oven at $50{ }^{\circ} \mathrm{C}$ for $10 \mathrm{~h}$ and then stored in an air-tight container for experimental use.

\section{Preparation of reduced graphene oxide (RG0)}

Fresh Abelmoschus esculentus (ladyfinger), a green vegetable locally known as 'bhindi,' was used in the synthesis of RGO. An extract of Abelmoschus esculentus was prepared by boiling its $20.0 \mathrm{~g}$ with $100 \mathrm{~mL}$ DDW for about $15 \mathrm{~min}$. After boiling, the extract was separated and collected into a flask by filtration using Whatman paper No. 1. After this, graphene oxide/water suspension (100 mg/100 mL) was mixed with the filtrate of vegetable extract and refluxed for $12 \mathrm{~h}$ at $100{ }^{\circ} \mathrm{C}$ for reduction. The appearance of a precipitate of black color indicates the formation of RGO. The precipitate was washed thoroughly and finally filtered by Whatman filter paper. The preparation of RGO from GO was monitored by using UV-visible spectroscopy.

\section{Preparation and characterization of reduced graphene oxide/polypyrrole (RGO/PPy) composite}

This composite was prepared in situ by oxidative polymerization of pyrrole. For this purpose, a dispersion of $2.0 \mathrm{~g}$ $\mathrm{FeCl}_{3}$ and $0.1 \mathrm{~g} \mathrm{RGO}$ was prepared in $50 \mathrm{~mL}$ of DDW under the ultrasonication for $30 \mathrm{~min}$. After this, $0.5 \mathrm{~g}$ pyrrole was added drop by drop, and the mixture was stirred at room temperature for $24 \mathrm{~h}$. After that, it was filtered, and the mass was washed with acetone followed by water and dried at $40{ }^{\circ} \mathrm{C}$ for $24 \mathrm{~h}$.

The presence of different functional groups was detected by Fourier transform infrared (FTIR) spectra of the components (RGO and PPy) and composite (RGO/PPY) were recorded in the spectral range of $4000-400 \mathrm{~cm}^{-1}$. The surface morphology of the composite was inspected with sample coated with gold by using a scanning electron microscope (SEM) (Model No. JSM6510LV, JEOL, Japan). The thermal stability of the RGO, PPy and RGO/PPy composite was examined by thermogravimetric analysis (TGA) with Shimadzu analyzer (Model No. DTG-60H) under a nitrogen atmosphere in the temperature range of $30-600{ }^{\circ} \mathrm{C}$. The particle size of the composite was analyzed using a transmission electron microscope (TEM, JEM 2100, JEOL, Japan).

\section{Preparation of glassy carbon electrode/reduced graphene oxide/polypyrrole/nitrate reductase (GCE/ RGO/PPy/NR) working electrode}

Initially, a GCE of $3 \mathrm{~mm}$ diameter was polished with $50 \mathrm{~nm}$ alumina slurry by using a velvet polishing pad. This was followed by its ultrasonification first in ethanol and then in water for $10 \mathrm{~min}$ each to make it free from contaminants and allowed to dry at room temperature. The electrode was electrochemically cleaned in a $1.0 \mathrm{M} \mathrm{H}_{2} \mathrm{SO}_{4}$ solution by cycling the potential between -1 and $+1 \mathrm{~V}$ using a reference $\mathrm{Ag} /$ $\mathrm{AgCl}$, at a sweep rate of $50 \mathrm{mV} \mathrm{s}^{-1}$. After drying, $4 \mu \mathrm{L}$ of the prepared RGO/PPy dispersion in dimethylformamide was drop cast on the GCE and was allowed to dry at room temperature for an hour. To maintain the enzyme activity of nitrate reductase, $10 \mathrm{mg}$ of it was dissolved in $1 \mathrm{~mL}$ of phosphate buffer solution of $\mathrm{pH}$ 7.3. $4.0 \mu \mathrm{L}$ of $\mathrm{NR}$ solution was applied on the dried RGO/PPy nanocomposite-modified electrode and allowed to adsorb at room temperature till it gets dried and was kept in the refrigerator until the studies were undertaken.

\section{Results and discussion}

\section{Characterization of electrode materials}

The formation of RGO from GO was tested by examining their interaction with UV rays. The absorption spectra of GO and the prepared RGO are shown in Fig. 1. A characteristic peak of GO at $\lambda_{\max }$ of $230 \mathrm{~nm}$ (curve a) is assigned to the $\pi \rightarrow \pi^{*}$ transition of aromatic $\mathrm{C}=\mathrm{C}$, while a hump near $298 \mathrm{~nm}$ is due to $n \rightarrow \pi^{*}$ transition of the carbonyl group (Zhang et al. 2011). The curve b of Fig. 1 shows an absorption peak at $263 \mathrm{~nm}$, which confirmed the formation of RGO (the reduced product of GO). The complete disappearance of the hump near $298 \mathrm{~nm}$ further confirmed the complete removal of oxygen functional groups from $\mathrm{GO}$ and the formation of RGO (Gnanaprakasam and Selvaraju 2014; Atarod et al. 2015).

Figure 2 shows the FTIR spectra of the components (RGO, PPy) and their composite (PPy/RGO). The FTIR spectrum of RGO shows a broad absorption at $3203 \mathrm{~cm}^{-1}$, while a number of strong-to-medium sharp peaks are observed at 1577, 1375, 1220 and $1053 \mathrm{~cm}^{-1}$. The broad band may be associated with the stretching of $\mathrm{O}-\mathrm{H}$ group. The sharp peak observed at $1577 \mathrm{~cm}^{-1}$ is due to $\mathrm{C}=\mathrm{C}$ stretching and corresponds to the skeletal vibration of graphene nanostructure (Lingappan et al. 2013). The peaks observed in the region between 1500 and $1000 \mathrm{~cm}^{-1}$ are

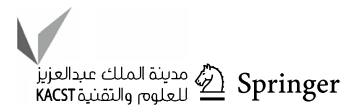


Fig. 1 UV-visible absorption spectra of $\mathbf{a}$ GO and $\mathbf{b}$ RGO

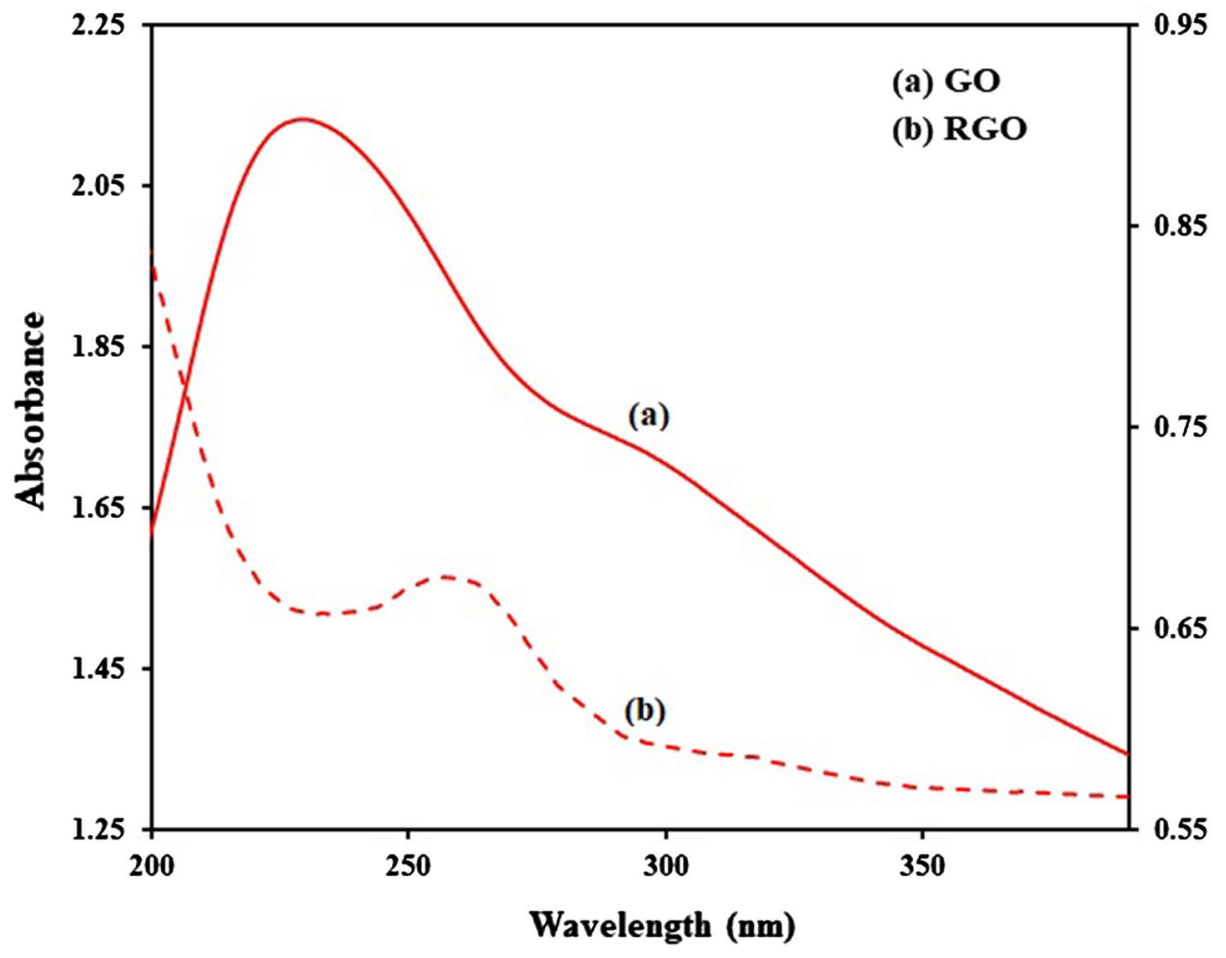

0.95

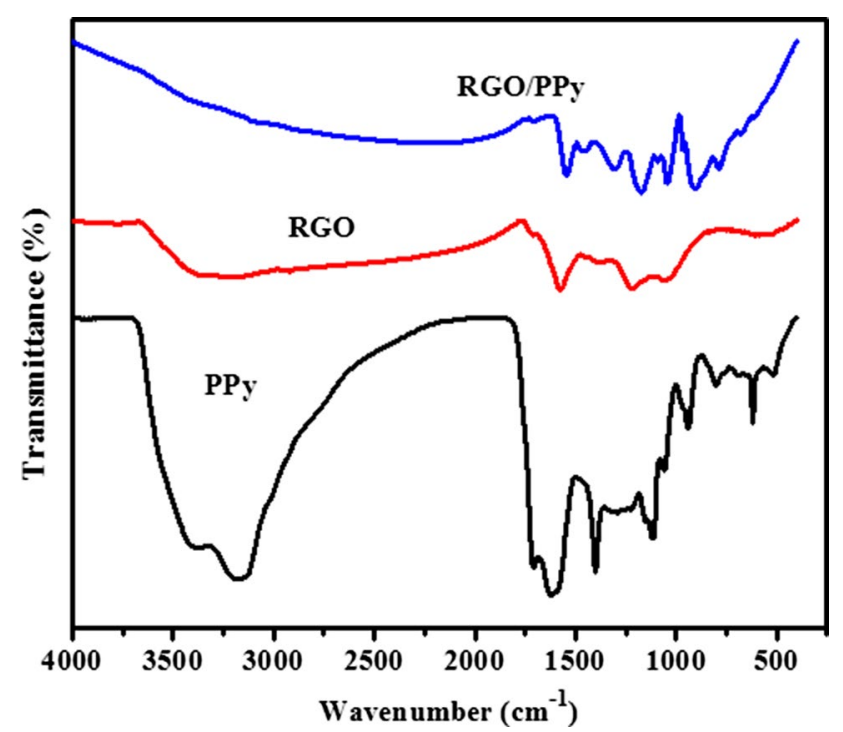

Fig. 2 FTIR spectra of RGO, PPy and RGO/PPy nanocomposite

probably assigned to stretching and strains of $\mathrm{C}-\mathrm{O}$ bonds as well as to deformations in the $\mathrm{O}-\mathrm{H}$ bond (Ribeiro et al. 2017). In the case of PPy, two broad bands at 3375 and $3179 \mathrm{~cm}^{-1}$ and a number of sharp peaks in the spectral range of $1708-619 \mathrm{~cm}^{-1}$ have been observed. However, in case of RGO/PPy, a very broad band near $2209 \mathrm{~cm}^{-1}$ and a number of sharp peaks have been located in the range of $1704-615 \mathrm{~cm}^{-1}$. The changes in FTIR peaks of PPy after its treatment with RGO indicate the agglomeration of RGO and PPy. This has further been confirmed by SEM studies. The SEM images shown in Fig. 3 display the morphologies of the as-synthesized RGO/PPy composite and the NR immobilized composite (PPy/RGO/NR). Figure 3a clearly reflects that RGO layers covering the PPy chains have a coarse and irregular surface morphology. It is clearly seen from the figure that the surface of RGO was entirely covered by PPy. The result is in agreement with that reported earlier $(\mathrm{Wu}$ et al. 2015) suggesting that RGO having larger size was not only connected with PPy chains, but also covered by PPy. The compact association between RGO and PPy achieved after chemical polymerization would possibly facilitate electron conduction that would lead to the improved electrochemical performance of the composite. After deposition of NR enzyme in the composite matrix (Fig. 3b), the relatively homogeneous surface was observed that reveals the uniform agglomeration of the NR on the surface of the composite material.

The relative thermal stabilities of RGO, PPy and RGO/ PPy composite were examined and analyzed by thermogravimetric studies. The weight loss (TGA) and derivative weight loss (DTG) of RGO, PPy and RGO/PPy are presented in Fig. 4. This thermogram indicates the higher stability of the nanocomposite over the individual species. During the early stage, the weight loss was about $10 \%$ each for RGO and PPy while 6\% for RGO/PPy at the temperature rise of about $100{ }^{\circ} \mathrm{C}$. At a later stage, the weight loss, respectively, goes to 1.6 and $2.5 \%$ on a further increase in temperature from 100 to $150{ }^{\circ} \mathrm{C}$. The weight loss in these temperature ranges might be due to evaporation of moisture. It is remarkable that on a further 

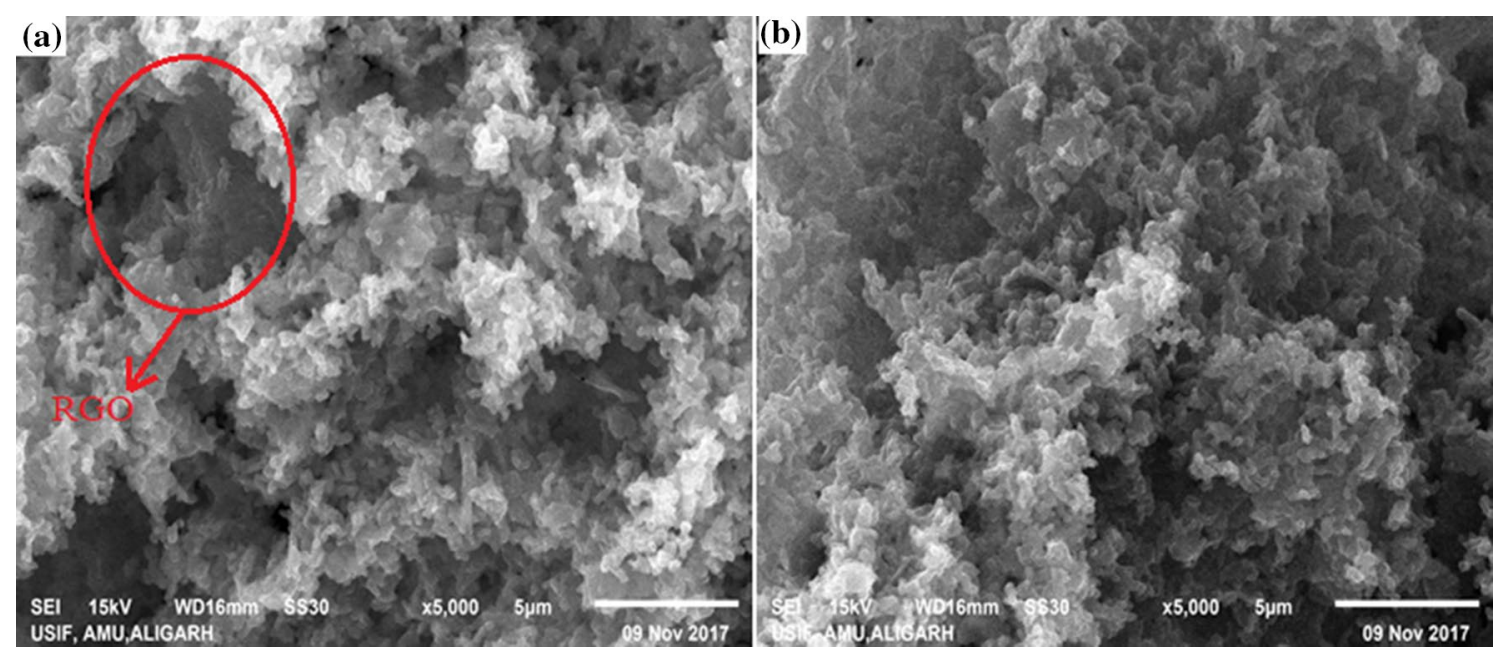

Fig. 3 SEM images of a RGO/PPy composite and b RGO/PPy/NR

Fig. 4 TGA and DTG curves of RGO, PPy and RGO/PPy nanocomposite

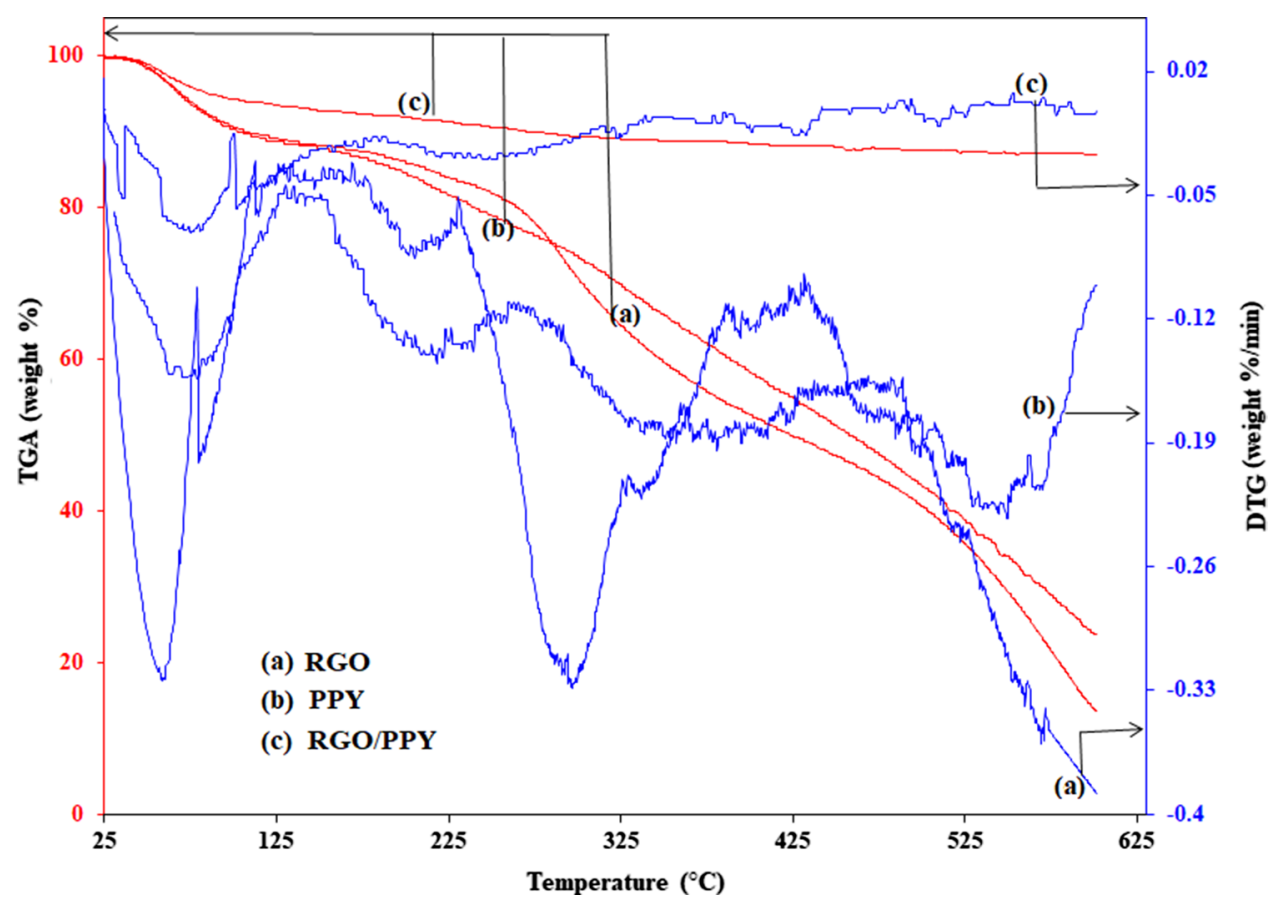

The TEM image of the RGO/PPy nanocomposite shown in Fig. 5 indicates that the particles are of different shapes having a different size ranging from 17 to $95 \mathrm{~nm}$.

\section{Cyclic voltammetry of GCE/RGO/PPy/NR electrode}

The cyclic voltammetric studies of GCE/RGO/PPy/NR were carried out in the absence as well the presence of 0.01 molar nitrate in $0.1 \mathrm{M} \mathrm{KCl}$ electrolyte at $100 \mathrm{mV} \mathrm{s}^{-1}$ scan rate, increase in temperature up to $600{ }^{\circ} \mathrm{C}$, there is a total weight loss of about 86, 76 and $27 \%$ for RGO, PPy and $\mathrm{RGO} / \mathrm{PPy}$, respectively. TGA plot also clearly indicates that for the same weight loss of RGO/PPy composite, the much higher temperature is required in comparison with that for individual components, RGO and PPy. Thus, it may be concluded the composite RGO/PPy is considerably more thermally stable than their components. 


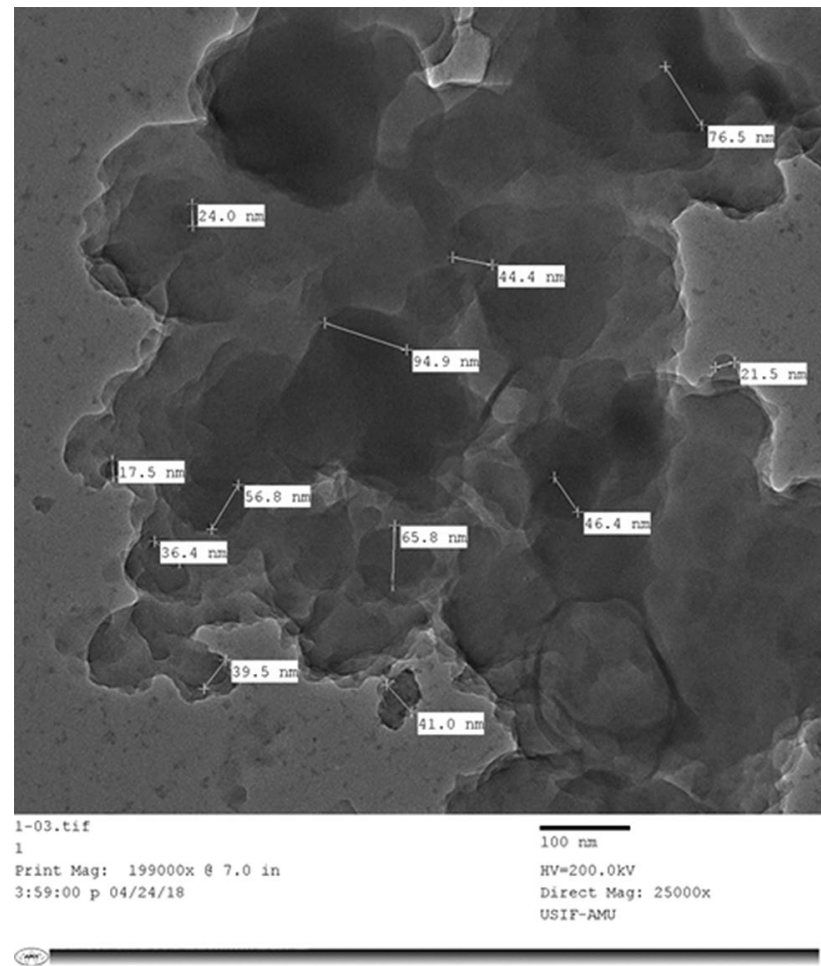

Fig. 5 TEM micrograph of RGO/PPy nanocomposite

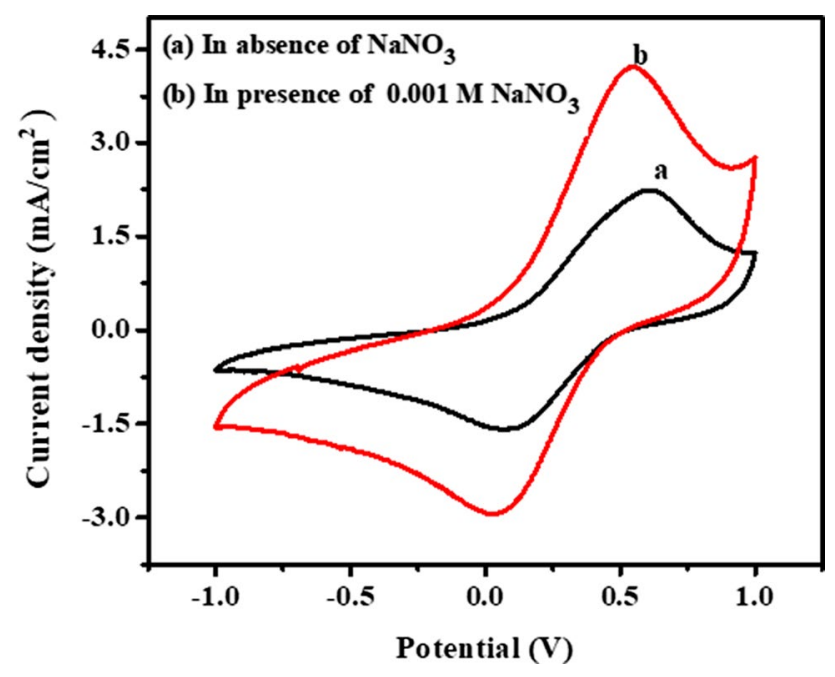

Fig. $6 \mathrm{CV}$ of $\mathrm{GCE} / \mathrm{RGO} / \mathrm{PPy} / \mathrm{NR}$ in the absence and presence of $10 \mathrm{mM} \mathrm{NaNO}_{3}$ in $0.1 \mathrm{M} \mathrm{KCl}$ solution (scan rate $=100 \mathrm{mV} \mathrm{s}^{-1}$ )

and results are graphically shown in Fig. 6. In the absence of nitrate, a feeble current of $2.12 \mathrm{~mA} \mathrm{~cm}^{-2}$ was observed. However, in the presence of nitrate, the current density of GCE/RGO/PPy/NR electrode reached $4.24 \mathrm{~mA} \mathrm{~cm}^{-2}$. This indicates that GCE/RGO/PPy/NR electrode effectively catalyzed the reduction of nitrate to nitrite.

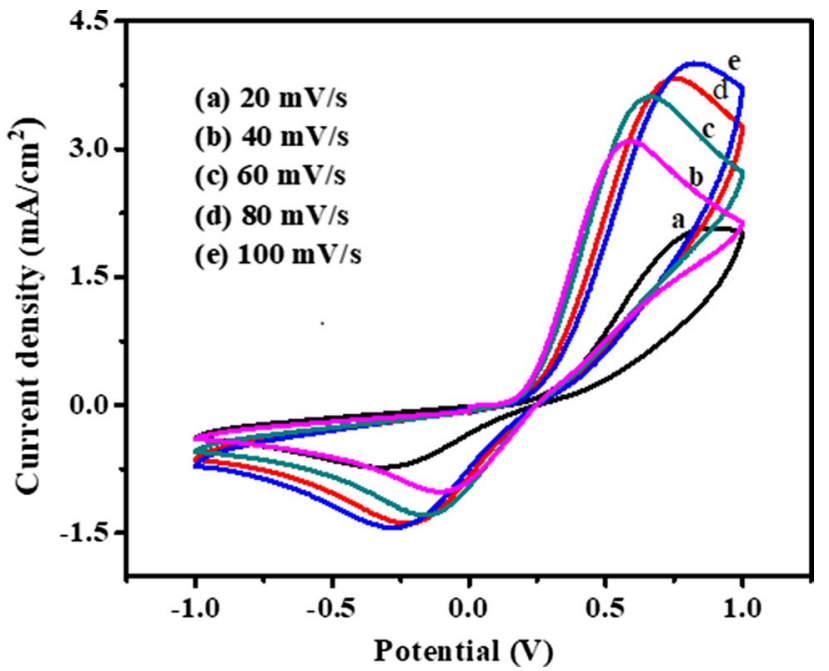

Fig. 7 Plot of current density versus applied voltage in $0.1 \mathrm{M} \mathrm{KCl}$ solution containing $10 \mathrm{mM} \mathrm{NaNO}$ at different scan rates ranging from 20 to $100 \mathrm{mV} \mathrm{s}^{-1}$

\section{Effect of scan rate}

The effect of scan rates on the electrocatalytic activity of GCE/RGO/PPy/NR electrode for the determination of nitrate was also investigated. The variation in current density against applied voltage is plotted in Fig. 7 at different scan rates $\left(20,40,60,80\right.$, and $\left.100 \mathrm{mV} \mathrm{s}^{-1}\right)$. This figure indicates that there is a continuous increase in the cathodic and anodic peak current (indicated by a, b, c, d and e) with the increase in scan rate. The dependency of redox peak current on scan rate suggests that the nitrate reduction by the GCE/RGO/PPy/NR-modified bio-electrode is dominated by a surface-controlled phenomenon. Hence, it can be inferred from the results that scan rate has a significant effect on the electrochemical process which includes a mixture of adsorption- and diffusion-controlled processes (Inamuddin et al. 2016; Haque et al. 2017a, b; Perveen et al. 2017, 2018a, b; Beenish et al. 2018).

The surface concentration of RGO/PPY/NR confined on the glassy carbon electrode can be evaluated using the following Brown Anson model (Nicholson 1965).

$I_{\mathrm{p}}=n^{2} \mathrm{~F}^{2} I * A v / 4 \mathrm{R} T$

where $I_{\mathrm{p}}$ is peak current, $n$ is the number of electrons transferred, $\mathrm{F}$ is the Faraday constant $\left(96,484 \mathrm{C} \mathrm{mol}^{-1}\right), I^{*}$ is the surface concentration of the modified bio-composite, $A$ is the electrode surface area of GCE $\left(0.07 \mathrm{~cm}^{2}\right), \nu$ is the scan 


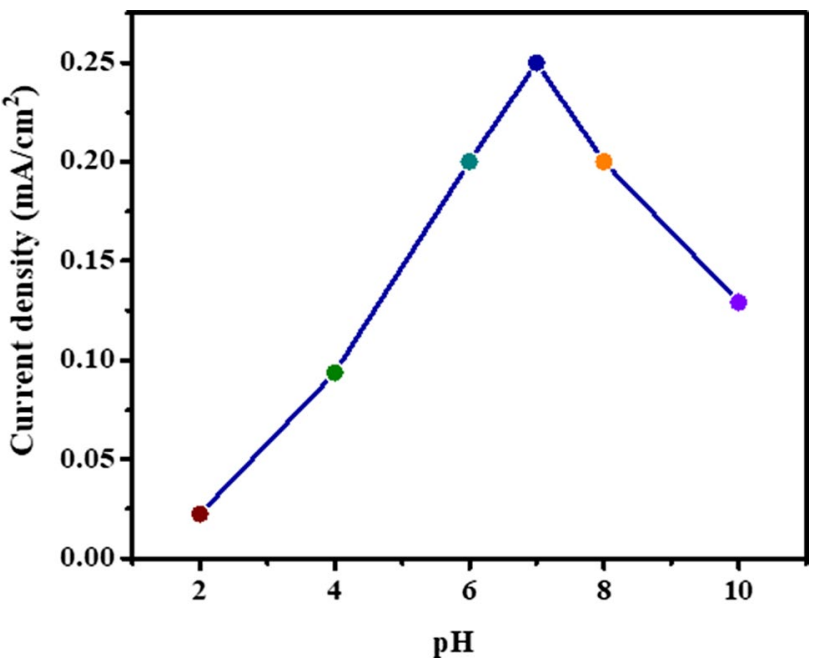

Fig. 8 The effect of $\mathrm{pH}$ on the catalytic response of the biosensor (scan rate $=100 \mathrm{mV} \mathrm{s}^{-1}$ )

rate of $\left(100 \mathrm{mV} \mathrm{s}^{-1}\right), \mathrm{R}$ is the gas constant, and $T$ is the absolute temperature in Kelvin. The surface concentration of bio-electroactive species RGO/PPy/NR deposited on the surface of GCE was evaluated to be $1.4 \times 10^{-10} \mathrm{~mol} \mathrm{~cm}^{-2}$.

\section{Effect of pH}

The effect of $\mathrm{pH}$ (ranging from 2 to 10 ) on the sensing performance of the modified GCE/RGO/PPy/NR in PBS was determined using cyclic voltammetry, and the result is shown in Fig. 8. The response of the biosensor regarding current density was found to increase with the increase in $\mathrm{pH}$ up to 7, but beyond that, the sensing response started declining. Thus, a value of 7 has been established as an optimum $\mathrm{pH}$ of the medium. This may be attributed to weak enzyme activity at low as well as high $\mathrm{pH}$ values since the reduction of nitrate to nitrite requires acidic medium, while the increase in alkalinity slows down the reduction step, and thus, a decline in peak current density is observed (Dinçkaya et al. 2010). It is evident from the results that $\mathrm{pH}$ has a considerable effect on the performance of the nitrate biosensor, and the optimum $\mathrm{pH}$ range for the developed biosensor is $2-7$, while the maximum value current density was observed at $\mathrm{pH} 7$. The optimum value $\mathrm{pH}$ was confirmed by performing the repeated experiments under the same laboratory conditions.

\section{Linear sweep voltammetry of GCE/RGO/PPy/NR electrode}

The linear sweep voltammetry (LSV) of GCE/RGO/PPy/ NR electrode was performed at different concentrations of sodium nitrate in potassium chloride. The LSV curves

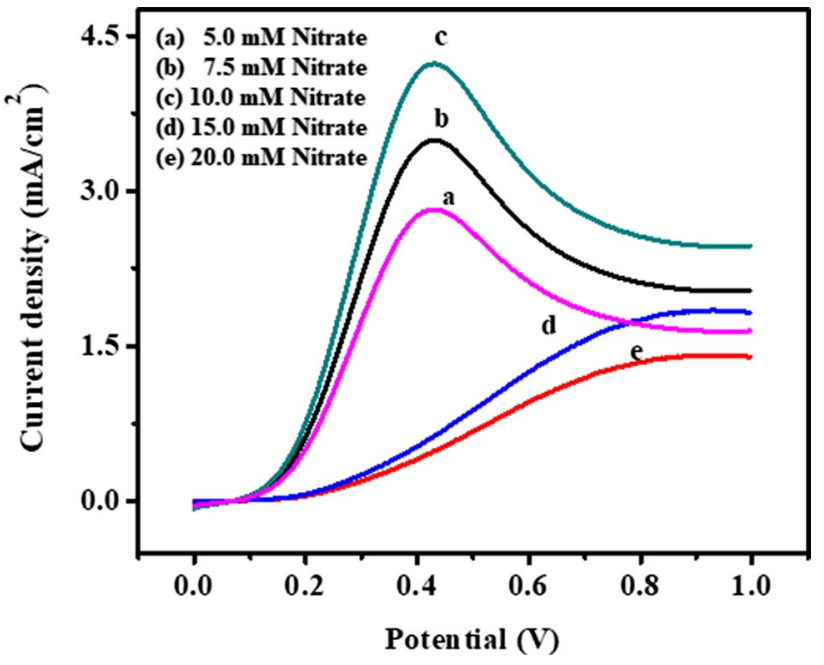

Fig. $9 \mathrm{LSVs}$ of the GCE/RGO/PPy/NR-modified GC electrode in $0.1 \mathrm{M} \mathrm{KCl}$ at different concentrations of nitrate a $5 \mathrm{mM}$ b $7.5 \mathrm{mM}$ c $10 \mathrm{mM} \mathrm{d} 15 \mathrm{mM}$ and e $20 \mathrm{mM}$ at room temperature with a potential scan rate of $100 \mathrm{mV} \mathrm{s}^{-1}$

shown in Fig. 9 indicate that the catalytic current increases with the increase in applied voltage up to a peak value depending upon the nitrate concentration, and after that it starts decreasing. This figure further specifies that the peak current density is strongly dependent on the concentration of sodium nitrate and observed to be increased from a value of $2.7 \mathrm{~mA} \mathrm{~cm}^{-2}$ at $5 \mathrm{mM}$ (curve a) to a maximum value of 4.24 $\mathrm{mA} \mathrm{cm}{ }^{-2}$ at $10 \mathrm{mM}$ (curve c), and after that it became start to decrease. Thus, the optimum concentration of sodium nitrate for peak current density has been established to be $10 \mathrm{mM}$. At further higher concentrations of nitrate (curves $\mathrm{d}$ and e), significantly poor result is obtained. To check the

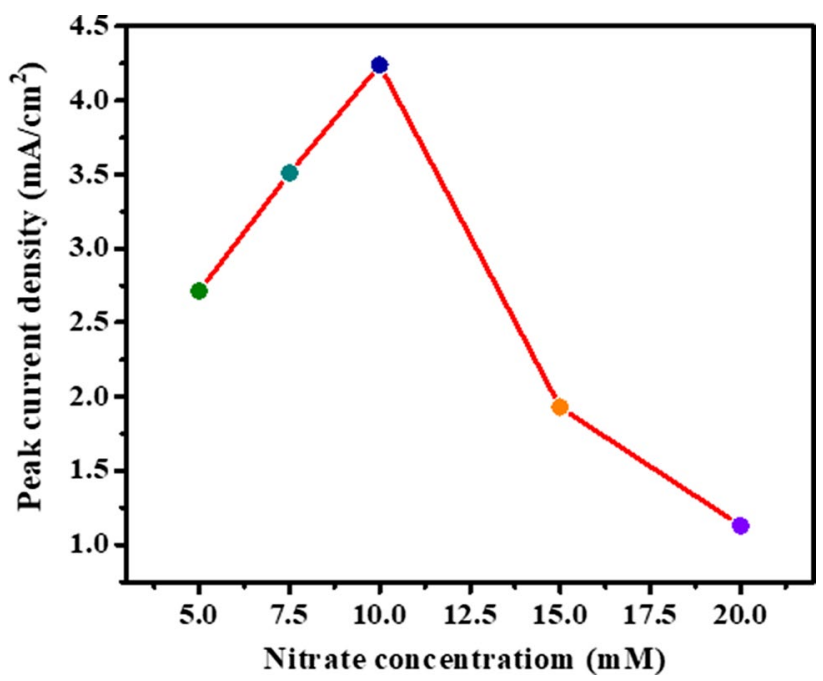

Fig. 10 Calibration curve for peak current versus nitrate concentration $\left(\right.$ scan rate $=100 \mathrm{mV} \mathrm{s}^{-1}$ ) 
Table 1 Limit of detection (LOD) of different types of biosensors

\begin{tabular}{llll}
\hline Biosensor & Substrate & LOD $(\mathrm{mM})$ & References \\
\hline PPy-NR-Azure A & $\mathrm{NaNO}_{3}$ & 0.010 & Sohail and Adeloju (2009) \\
CNT/PPy/NR & $\mathrm{NaNO}_{3}$ & 0.170 & Can et al. (2012) \\
Epoxy/AuNPs/NR & $\mathrm{NaNO}_{3}$ & 0.050 & Sachdeva and Hooda (2014) \\
PEDOT*/NR (nanowire) & $\mathrm{KNO}_{3}$ & $0.0016,0.0054 * *$ & Gokhale et al. (2015) \\
PEDOT*/NR (2D flat film) & $\mathrm{KNO}_{3}$ & 0.341 & Gokhale et al. (2015) \\
RGO/PPy/NR & $\mathrm{NaNO}_{3}$ & 0.275 & Present study \\
\hline
\end{tabular}

$*$ PEDOT $=$ Poly $(3,4$-ethylenedioxythiophene $), * *$ LOD depends on laboratory conditions performance and reproducibility of the results, the entire experiments were repeated. This decides the suitable concentration range for the effectiveness of the GCE/RGO/PPy/ NR biosensor for nitrate.

Figure 10 shows the calibration curve of current density versus concentration of nitrate. In the calibration curve, the plot so obtained reveals that the current density increases with the increase in sodium nitrate concentration up to $10 \mathrm{mM}$ attaining a maximum current density of 4.24 $\mathrm{mA} \mathrm{cm}{ }^{-2}$, and thereafter it starts to decrease. Therefore, the fabricated bio-electrode is capable of serving as a good nitrate biosensor up to the nitrate concentration of $10 \mathrm{mM}$.

\section{Working stability and reproducibility of the biosensor}

The operational stability and reproducibility of the GCE/ $\mathrm{RGO} / \mathrm{PPy} / \mathrm{NR}$ biosensor were tested by the repeated experiments under similar conditions. The lowest concentration of the nitrate ions, which can be detected under the laboratory conditions, i.e., the limit of detection (LOD), has been evaluated by using the following equation (Gokhale et al. 2015):

$\mathrm{LOD}=\frac{3 \times S D}{m}$

where, $S D$ and $m$ represent the standard deviation and slope of the calibration curve. The value so obtained for the present biosensor is compared with that reported for the different nitrate biosensors by other investigators in Table 1 . The table indicates that the LOD of the present biosensor is in moderate range and performance of the sensor is very attractive if we consider cost-effective parameter.

Thus, the constructed biosensor electrode has a great significance as the electrochemical analysis of nitrate at GCE/PPy/RGO/NR biosensor proved to be cost-effective. The RGO used in the present work as a redox mediator was prepared from ladyfinger extract. In this context, it is much relevant to mention here that most of nitrate biosensors used mediator with relatively expensive materials (Sohail and Adeloju 2008, 2009; Adeloju and Sohail 2011).
Furthermore, the present biosensor is highly selective as it was tested in the presence of various anions $\left(\mathrm{HPO}_{4}^{2-}\right.$, $\left.\mathrm{H}_{2} \mathrm{PO}_{4}^{-}, \mathrm{ClO}_{4}^{-}, \mathrm{Cl}^{-}, \mathrm{SO}_{4}^{2-}, \mathrm{SO}_{3}^{-}\right)$and cations $\left(\mathrm{Al}^{3+}, \mathrm{Mg}^{2+}\right.$, $\mathrm{K}^{+}, \mathrm{NH}_{4}^{+}, \mathrm{K}^{+}, \mathrm{Ca}^{2+}, \mathrm{Mg}^{2+}$ ).

\section{Conclusion}

A good catalytic response of the developed GCE/RGO/PPy/ NR biosensor electrode indicates its potential to be used in the detection of hazardous nitrate ions in wastewaters. The nanocomposite of PPy with RGO imparted fairly high electrical conductivity and favorable stability to the electrode. It also served as a good matrix for the immobilization of the NR enzyme involved. The proposed electrode exhibited excellent electrocatalytic performance toward nitrate reduction and showed great selectivity toward the nitrate ions as well as low detection limit. The nitrate reductase deposited on the GCE/RGO/PPy carried direct electron transfer effectively from nitrate to the electrode. Nitrate reductase is an enzyme that assists the direct electron transfer from the active site of composite RGO/PPy electrode surface leading to the enhancement of current density up to $4.24 \mathrm{~mA} \mathrm{~cm}^{-2}$. Thus, the significant current density of fast direct electron transfer kinetics envisages its great prospects in the future for various applications. The developed biosensor has been established to be cost-effective, efficient, reliable and highly selective for nitrate ions present in water.

Acknowledgements The authors are thankful to the chairman, Department of Applied Chemistry, Faculty of Engineering and Technology, Aligarh Muslim University, for providing research facilities. Financial assistance from the Council of Science and Technology, Government of Uttar Pradesh, under the research Project No. CST/SERPD/D-282 dated 14-05-2015 is gratefully acknowledged.

Open Access This article is distributed under the terms of the Creative Commons Attribution 4.0 International License (http://creativeco mmons.org/licenses/by/4.0/), which permits unrestricted use, distribution, and reproduction in any medium, provided you give appropriate credit to the original author(s) and the source, provide a link to the Creative Commons license, and indicate if changes were made. 


\section{References}

Adeloju SB, Sohail M (2011) Azure A mediated polypyrrole-based amperometric nitrate biosensor. Electroanalysis 23:987-996. https ://doi.org/10.1002/elan.201000386

Alam SN, Sharma N, Kumar L (2017) Synthesis of graphene oxide (GO) by modified hummers method and its thermal reduction to obtain reduced graphene oxide (rGO)*. Graphene $06: 1-18$. https ://doi.org/10.4236/graphene.2017.61001

Atarod M, Nasrollahzadeh M, Sajadi SM (2015) Green synthesis of a $\mathrm{Cu} /$ reduced graphene oxide $/ \mathrm{Fe}_{3} \mathrm{O}_{4}$ nanocomposite using Euphorbia wallichii leaf extract and its application as a recyclable and heterogeneous catalyst for the reduction of 4-nitrophenol and rhodamine B. RSC Adv 5:91532-91543. https://doi.org/10.1039/ C5RA17269A

Atmeh M, Alcock-Earley BE (2011) A conducting polymer/Ag nanoparticle composite as a nitrate sensor. J Appl Electrochem 41:1341-1347. https://doi.org/10.1007/s10800-011-0354-4

Azimi A, Azari A, Rezakazemi M, Ansarpour M (2017) Removal of heavy metals from industrial wastewaters: a review. ChemBioEng Rev 4:37-59. https://doi.org/10.1002/cben.201600010

Barbier GG, Joshi RC, Campbell ER, (Bill) Campbell WH (2004) Purification and biochemical characterization of simplified eukaryotic nitrate reductase expressed in Pichia pastoris. Protein Expr Purif 37:61-71. https://doi.org/10.1016/j.pep.2004.05.021

Beenish, Inamuddin, Ahamed MI et al (2018) Biocompatible mediated bioanode prepared by using poly(3,4-ethylene dioxythiophene) poly(styrene sulfonate) (PEDOT:PSS) and sulfonated graphene oxide integrated enzyme for biofuel cells applications. Mater Sci Energy Technol. https://doi.org/10.1016/j.mset.2018.03.003

Beer DD, Sweerts J-PRA (1989) Measurement of nitrate gradients with an ion-selective microelectrode. Anal Chim Acta 219:351-356. https://doi.org/10.1016/S0003-2670(00)80369-4

Blount BC, Valentin-Blasini L (2006) Analysis of perchlorate, thiocyanate, nitrate and iodide in human amniotic fluid using ion chromatography and electrospray tandem mass spectrometry. Anal Chim Acta 567:87-93. https://doi.org/10.1016/j.aca.2006.02.010

Can F, Korkut Ozoner S, Ergenekon P, Erhan E (2012) Amperometric nitrate biosensor based on Carbon nanotube/Polypyrrole/Nitrate reductase biofilm electrode. Mater Sci Eng C 32:18-23. https:// doi.org/10.1016/j.msec.2011.09.004

Ciulu M, Ollivier N, Demelas C et al (2018) A highly-sensitive microplate fluorimetric method for the high-throughput determination of nitrate ion in aqueous compost extracts. Microchem J 138:424429. https://doi.org/10.1016/j.microc.2018.01.042

Cosnier S, Da Silva S, Shan D, Gorgy K (2008) Electrochemical nitrate biosensor based on poly(pyrrole-viologen) film-nitrate reductase-clay composite. Bioelectrochemistry 74:47-51. https://doi. org/10.1016/j.bioelechem.2008.04.011

Dinçkaya E, Akyilmaz E, Kemal Sezgintürk M, Nil Ertaş F (2010) Sensitive nitrate determination in water and meat samples by amperometric biosensor. Prep Biochem Biotechnol 40:119-128. https://doi.org/10.1080/10826060903558620

Ebrahimi-Gatkash M, Younesi H, Shahbazi A, Heidari A (2017) Amino-functionalized mesoporous MCM-41 silica as an efficient adsorbent for water treatment: batch and fixed-bed column adsorption of the nitrate anion. Appl Water Sci 7:1887-1901. https://doi. org/10.1007/s13201-015-0364-1

Edwards AC, Hooda PS, Cook Y (2001) Determination of nitrate in water containing dissolved organic carbon by ultraviolet spectroscopy. Int J Environ Anal Chem 80:49-59. https://doi. org/10.1080/03067310108044385

Gajaraj S, Fan C, Lin M, Hu Z (2013) Quantitative detection of nitrate in water and wastewater by surface-enhanced Raman spectroscopy. Environ Monit Assess 185:5673-5681. https://doi. org/10.1007/s10661-012-2975-4

Gao L, Barber-Singh J, Kottegoda S et al (2004) Determination of nitrate and nitrite in rat brain perfusates by capillary electrophoresis. Electrophoresis 25:1264-1269. https://doi.org/10.1002/ elps. 200305840

Gnanaprakasam P, Selvaraju T (2014) Green synthesis of self assembled silver nanowire decorated reduced graphene oxide for efficient nitroarene reduction. RSC Adv 4:24518-24525. https://doi. org/10.1039/C4RA01798F

Gokhale AA, Lu J, Weerasiri RR et al (2015) Amperometric detection and quantification of nitrate ions using a highly sensitive nanostructured membrane electrocodeposited biosensor array. Electroanalysis 27:1127-1137. https://doi.org/10.1002/elan.201400547

Haque SU, Inamuddin Nasar A et al (2017a) Optimization of glucose powered biofuel cell anode developed by polyaniline-silver as electron transfer enhancer and ferritin as biocompatible redox mediator. Sci Rep 7:12703. https://doi.org/10.1038/s41598-01712708-6

Haque SU, Inamuddin, Nasar A, Mohamed Asiri A (2017b) Fabrication and characterization of electrochemically prepared bioanode (polyaniline/ferritin/glucose oxidase) for biofuel cell application. Chem Phys Lett. https://doi.org/10.1016/j.cplet t.2017.12.035

Huber C, Klimant I, Krause C et al (2001) Nitrate-selective optical sensor applying a lipophilic fluorescent potential-sensitive dye. Anal Chim Acta 449:81-93. https://doi.org/10.1016/S0003 $-2670(01) 01363-0$

Inamuddin, Haque SU, Naushad M (2016) Electrochemical studies of biocatalytic anode of sulfonated graphene/ferritin/glucose oxidase layer-by-layer biocomposite films for mediated electron transfer. Enzyme Microb Technol 87-88:29-36. https://doi.org/10.1016/j. enzmictec.2016.02.011

Kiang C-H, Kuan SS, Guilbault GG (1978) Enzymic determination of nitrate: fluorometric detection after reduction with nitrate reductase. Anal Chem 50:1323-1325. https://doi.org/10.1021/ac500 $31 \mathrm{a} 032$

Lingappan N, Gal Y-S, Lim KT (2013) Synthesis of reduced graphene oxide/polypyrrole conductive composites. Mol Cryst Liq Cryst 585:60-66. https://doi.org/10.1080/15421406.2013.849510

López Pasquali CE, Fernández Hernando P, Durand Alegría JS (2007) Spectrophotometric simultaneous determination of nitrite, nitrate and ammonium in soils by flow injection analysis. Anal Chim Acta 600:177-182. https://doi.org/10.1016/j.aca.2007.03.015

Lu J, Do I, Drzal LT et al (2008) Nanometal-decorated exfoliated graphite nanoplatelet based glucose biosensors with high sensitivity and fast response. ACS Nano 2:1825-1832. https://doi. org/10.1021/nn800244k

Mohr GJ, Lehmann F, Östereich R et al (1997) Investigation of potential-sensitive fluorescent dyes for application in nitrate sensitive polymer membranes. Fresenius J Anal Chem 357:284-291. https ://doi.org/10.1007/s002160050154

Moorcroft M (2001) Detection and determination of nitrate and nitrite: a review. Talanta 54:785-803. https://doi.org/10.1016/S0039 $-9140(01) 00323-\mathrm{X}$

Moorcroft MJ, Davis J, Compton RG (2001) Detection and determination of nitrate and nitrite: a review. Talanta 54:785-803

Nicholson RS (1965) Theory and application of cyclic voltammetry for measurement of electrode reaction kinetics. Anal Chem 37:13511355. https://doi.org/10.1021/ac60230a016

Pasquali CEL, Gallego-Picó A, Hernando PF et al (2010) Two rapid and sensitive automated methods for the determination of nitrite and nitrate in soil samples. Microchem J 94:79-82. https://doi. org/10.1016/j.microc.2009.09.005 
Paulchamy B, Arthi G, Lignesh BD (2015) A simple approach to stepwise synthesis of graphene oxide nanomaterial. J Nanomed Nanotechnol. https://doi.org/10.4172/2157-7439.1000253

Perveen R, Inamuddin Haque SU et al (2017) Electrocatalytic performance of chemically synthesized PIn-Au-SGO composite toward mediated biofuel cell anode. Sci Rep 7:13353. https://doi. org/10.1038/s41598-017-13539-1

Perveen R, Inamuddin Nasar A et al (2018a) Synthesis and characterization of a novel electron conducting biocomposite as biofuel cell anode. Int J Biol Macromol 106:755-762. https://doi. org/10.1016/j.ijbiomac.2017.08.074

Perveen R, Nasar A, Inamuddin et al (2018b) Optimization of $\mathrm{MnO}_{2}$-graphene/polythioaniline $\left(\mathrm{MnO}_{2}\right.$-G/PTA) hybrid nanocomposite for the application of biofuel cell bioanode. Int J Hydrogen Energy. https://doi.org/10.1016/j.ijhydene.2018.06.070

Qamruzzaman, Nasar A (2014a) Treatment of acetamiprid insecticide from artificially contaminated water by colloidal manganese dioxide in the absence and presence of surfactants. RSC Adv 4:6284462850. https://doi.org/10.1039/c4ra09685a

Qamruzzaman, Nasar A (2014b) Kinetics of metribuzin degradation by colloidal manganese dioxide in absence and presence of surfactants. Chem Pap 68:65-73. https://doi.org/10.2478/s1169 6-013-0424-7

Rezakazemi M, Maghami M, Mohammadi T (2017) High loaded synthetic hazardous wastewater treatment using lab-scale submerged ceramic membrane bioreactor. Period Polytech Chem Eng 62:299-304. https://doi.org/10.3311/PPch.11459

Rezakazemi M, Khajeh A, Mesbah M (2018a) Membrane filtration of wastewater from gas and oil production. Environ Chem Lett 16:367-388. https://doi.org/10.1007/s10311-017-0693-4

Rezakazemi M, Maghami M, Mohammadi T (2018b) Wastewaters treatment containing phenol and ammonium using aerobic submerged membrane bioreactor. Chem Cent J 12:79. https://doi. org/10.1186/s13065-018-0450-1

Ribeiro I, Yotsumoto-Neto S, dos Santos W et al (2017) Improved NADH electroanalysis on nickel(II) phthalocyanine tetrasulfonic acid/calf thymus deoxyribonucleic acid/reduced graphene oxide composite. J Braz Chem Soc. https://doi.org/10.21577/01035053.20170030

Sachdeva V, Hooda V (2014) A new immobilization and sensing platform for nitrate quantification. Talanta 124:52-59. https://doi. org/10.1016/j.talanta.2014.02.014

Shakoor S, Nasar A (2016) Removal of methylene blue dye from artificially contaminated water using citrus limetta peel waste as a very low cost adsorbent. J Taiwan Inst Chem Eng 66:154-163. https:// doi.org/10.1016/j.jtice.2016.06.009

Shakoor S, Nasar A (2018) Adsorptive decontamination of synthetic wastewater containing crystal violet dye by employing Terminalia arjuna sawdust waste. Groundw Sustain Dev 7:30-38. https://doi. org/10.1016/j.gsd.2018.03.004

Sharma S, Bhattacharya A (2017) Drinking water contamination and treatment techniques. Appl Water Sci 7:1043-1067. https://doi. org/10.1007/s13201-016-0455-7
Sohail M, Adeloju SB (2008) Electroimmobilization of nitrate reductase and nicotinamide adenine dinucleotide into polypyrrole films for potentiometric detection of nitrate. Sensors Actuators B Chem 133:333-339. https://doi.org/10.1016/j.snb.2008.02.032

Sohail M, Adeloju SB (2009) Fabrication of redox-mediator supported potentiometric nitrate biosensor with nitrate reductase. Electroanalysis 21:1411-1418. https://doi.org/10.1002/elan.200804542

Sohail M, Adeloju SB (2016) Nitrate biosensors and biological methods for nitrate determination. Talanta 153:83-98. https://doi. org/10.1016/j.talanta.2016.03.002

Sohail M, De Marco R, Lamb K, Bakker E (2012) Thin layer coulometric determination of nitrate in fresh waters. Anal Chim Acta 744:39-44. https://doi.org/10.1016/j.aca.2012.07.026

Somnam S, Jakmunee J, Grudpan K et al (2008) Determination of nitrite and nitrate in water samples by an automated hydrodynamic sequential injection method. Anal Sci 24:1599-1603

Soropogui K, Sigaud M, Vittori O (2006) Alert electrodes for continuous monitoring of nitrate ions in natural water. Electroanalysis 18:2354-2360. https://doi.org/10.1002/elan.200603671

Tsikas D, Gutzki F-M, Rossa S et al (1997) Measurement of nitrite and nitrate in biological fluids by gas chromatography-mass spectrometry and by the Griess assay: problems with the Griess assaysolutions by gas chromatography-mass spectrometry. Anal Biochem 244:208-220. https://doi.org/10.1006/abio.1996.9880

Tu X, Xiao B, Xiong J, Chen X (2010) A simple miniaturised photometrical method for rapid determination of nitrate and nitrite in freshwater. Talanta 82:976-983. https://doi.org/10.1016/j.talan ta.2010.06.002

US-EPA United States Environmental Protection Agency, National Primary Drinking Water Regulations

Wang J, Wang L, Di J, Tu Y (2008) Disposable biosensor based on immobilization of glucose oxidase at gold nanoparticles electrodeposited on indium tin oxide electrode. Sensors Actuators B Chem 135:283-288. https://doi.org/10.1016/j.snb.2008.08.023

Ward MH, DeKok TM, Levallois P et al (2005) Workgroup report: drinking-water nitrate and health-recent findings and research needs. Environ Health Perspect 113:1607-1614. https://doi. org/10.1289/ehp. 8043

Wu F, Xie A, Sun M et al (2015) Reduced graphene oxide (RGO) modified spongelike polypyrrole (PPy) aerogel for excellent electromagnetic absorption. J Mater Chem A 3:14358-14369. https:// doi.org/10.1039/C5TA01577D

Zhang Z, Chen H, Xing C et al (2011) Sodium citrate: a universal reducing agent for reduction/decoration of graphene oxide with au nanoparticles. Nano Res 4:599-611. https://doi.org/10.1007/ s12274-011-0116-y

Publisher's Note Springer Nature remains neutral with regard to jurisdictional claims in published maps and institutional affiliations. 